\title{
Guidance for noise reduction provided by tree belts
}

\author{
Chih-Fang Fang ${ }^{a}, *$, Der-Lin Ling ${ }^{b}$ \\ a Department of Landscape Design and Management, National Chin-Yi Institute of Technology, 35 Lane 215, \\ Section 1, Chung-Shan Road, Taiping, Taichung 411, Taiwan, ROC \\ b Department of Horticulture, National Taiwan University, Taipei 106, Taiwan, ROC
}

Received 22 June 2003; received in revised form 14 January 2004; accepted 19 January 2004

\begin{abstract}
The effects of noise reduction of six tree belts were examined. An amplifier was placed in front of each tree belt, while a noise meter was placed at various heights and distances behind the tree belt. Net noise reduction effect termed as "relative attenuation" was obtained by subtracting the sound pressure level at each measurement site behind the tree belt from the sound pressure level at equal distances over open ground. Five parameters, including visibility, height, and width of the tree belt, height of receiver and noise source, and the distance between noise source and receiver, were studied. A multiple regression model demonstrating the order of importance of the five parameters in relation to relative attenuation was developed. The five parameters were then transformed into three-dimensionless parameters, i.e., $h^{\prime}$ : receiver and noise source height/tree height, $d^{\prime}$ : distance between noise source and receiver/tree height, and $m^{\prime}$ : belt width/visibility. By plotting the relative attenuation on the coordinate axis of $h^{\prime}, d^{\prime}$ and $m^{\prime}$ and curve fitting, a three-dimensionless map of noise reduction by tree belts was formed. The map can be used as guidance in designing three belts for noise reduction in environmental planning.
\end{abstract}

(c) 2004 Elsevier B.V. All rights reserved.

Keywords: Environmental design; Green belt; Noise control

\section{Introduction}

Tree belts situated between the noise source and the receiver can reduce the noise level perceived by the receiver (Kragh, 1979). Wide tree belts which exceed $30 \mathrm{~m}$ could reduce the noise by $4-8 \mathrm{~dB}$ A (Eyring, 1946; Reethof, 1973; Cook and Haverbeke, 1974). While a wide belt of sparse trees may reduce the noise effectively, it may not be always practical in landscape design. In order to investigate the effect of noise reduction by narrow tree belts, six dense and narrow tree belts were chosen and the noise reduction effect behind them was studied. Parameters such

\footnotetext{
* Corresponding author. Tel.: +886-4-23924505x8114; fax: +886-4-23930737.

E-mail address: ivyfung.tw@yahoo.com.tw (C.-F. Fang).
}

as visibility in the tree belt (visibility), tree height, belt width, receiver and noise source height, and the distance between noise source and receiver (distance) were included in the observations. Then the above parameters were transformed into three-dimensionless parameters to interpret the effect of noise reduction. Finally, a map showing the relationships between the three-dimensionless parameters and the effectiveness of noise reduction were constructed.

\section{Materials and methods}

\subsection{Materials}

Six kinds of tree belts which are common as hedges in Taiwan were chosen for the study. They were grown 
Table 1

Characteristics of six tree belts used in the experiment

\begin{tabular}{|c|c|c|c|c|c|c|c|c|c|c|c|c|}
\hline Species & $\begin{array}{l}\text { Tree } \\
\text { visibility } \\
\text { (m) }\end{array}$ & $\begin{array}{l}\text { Tree } \\
\text { height } \\
\text { (m) }\end{array}$ & $\begin{array}{l}\text { Belt } \\
\text { length } \\
\text { (m) }\end{array}$ & $\begin{array}{l}\text { Belt } \\
\text { width } \\
\text { (m) }\end{array}$ & $\begin{array}{l}\text { Interval } \\
(\mathrm{m})\end{array}$ & Arrangement ${ }^{\mathrm{a}}$ & $\begin{array}{l}\text { Measuring } \\
\text { site (m) }\end{array}$ & $\begin{array}{l}\text { Receiver and noise } \\
\text { source height }(\mathrm{m})\end{array}$ & $h^{\prime}$-value ${ }^{b}$ & $m^{\prime}$-value ${ }^{b}$ & $d^{\prime}$-value ${ }^{b}$ & Location \\
\hline $\begin{array}{l}\text { Casuarina nana Sieber } \\
\text { ex Spreng. }\end{array}$ & 0.8 & 2 & 100 & 2 & $0.3 \times 0.3$ & Crossing & $7,12, \ldots, 22$ & $\begin{array}{l}0.30,0.60,0.80 \\
1.00,1.20,1.40 \\
1.80\end{array}$ & $\begin{array}{l}0.15,0.3,0.4, \\
0.5,0.6,0.7, \\
0.9\end{array}$ & 2.5 & $3.5,6.0,8.5,11.0$ & Shin-chu city \\
\hline Casuarina equisetifolia & 1.9 & 5 & 80 & 3 & $1.5 \times 1.5$ & Random & $7,12, \ldots, 62$ & $0.75,1.50,3.00$ & $0.15,0.3,0.6$ & 1.6 & $1.4,2.4,3.4,4.4, \ldots, 12.4$ & Shin-chu city \\
\hline $\begin{array}{l}\text { Duranta repens } \\
\text { "Golden leaves" }\end{array}$ & 0.8 & 2.5 & 50 & 1.2 & $0.5 \times 0.5$ & Random & $7,12, \ldots, 22$ & $0.38,0.75,1.50$ & $0.15,0.3,0.6$ & 1.5 & $2.8,4.8,6.8,8.8$ & Taipei city \\
\hline $\begin{array}{l}\text { Ficus microcarpa L.f. } \\
\text { "Golden leaves" }\end{array}$ & 1.5 & 3.2 & 50 & 3 & $1.5 \times 1.5$ & Random & $7,12, \ldots, 32$ & $0.48,0.96,1.92$ & $0.15,0.3,0.6$ & 2 & $2.2,3.8,5.3,6.9,8.4,10.0$ & Shin-chu city \\
\hline Hibiscus rosa-sinensis & 1 & 2.5 & 60 & 1.8 & $0.4 \times 0.4$ & Random & $7,12 \ldots 32$ & $0.38,0.75,1.50$ & $0.15,0.3,0.6$ & 1.8 & $2.8,4.8,6.8,8.8,10.8,12.8$ & Chu-don town \\
\hline Murraya paniculata & 1.2 & 1.2 & 60 & 2.5 & $0.3 \times 0.3$ & Random & $7,12, \ldots, 22$ & $0.18,0.36,0.72$ & $0.15,0.3,0.6$ & 2.1 & $5.8,10.0,14.2,18.3$ & I-Lan city \\
\hline
\end{tabular}

a Arrangement: crossing ( $\ldots$ : $)$; random (\$

${ }^{\mathrm{b}} h^{\prime}$ : receiver and noise source height/tree height; $m^{\prime}$ : belt width/visibility; $d^{\prime}$ : distance/tree height. 
on flat areas. The ambient noise was maintained at $48 \pm$ $2 \mathrm{~dB}$ A. Each tree belt exceeded $50 \mathrm{~m}$ in length beyond which belt length has no effect on noise reduction according to Fang and Ling (2003). The characteristics of the six tree belts are shown in Table 1 .

\subsection{Experimental design}

A centerline was drawn perpendicular to the length of the tree belt (Fig. 1). Two transecting lines, A and $\mathrm{B}$, one on each side of and $2.5 \mathrm{~m}$ apart from the centerline were then drawn. A noise source was placed on each of the transecting line at the point $2 \mathrm{~m}$ away from the tree belts. The first noise measuring site was located $5 \mathrm{~m}$ behind the tree belt on the transecting lines. Subsequent measuring sites (4-12 as situation permits) were located at spots with $5 \mathrm{~m}$ increments. The noise source height was the same as receiver height. Various receiver heights and noise source heights were tested for each tree belt (Table 1). The sound pressure level at each measuring site on the two transecting lines was averaged to obtain the mean. Similar experiments were conducted on the open ground near each tree belt. The difference between the mean sound pressure level

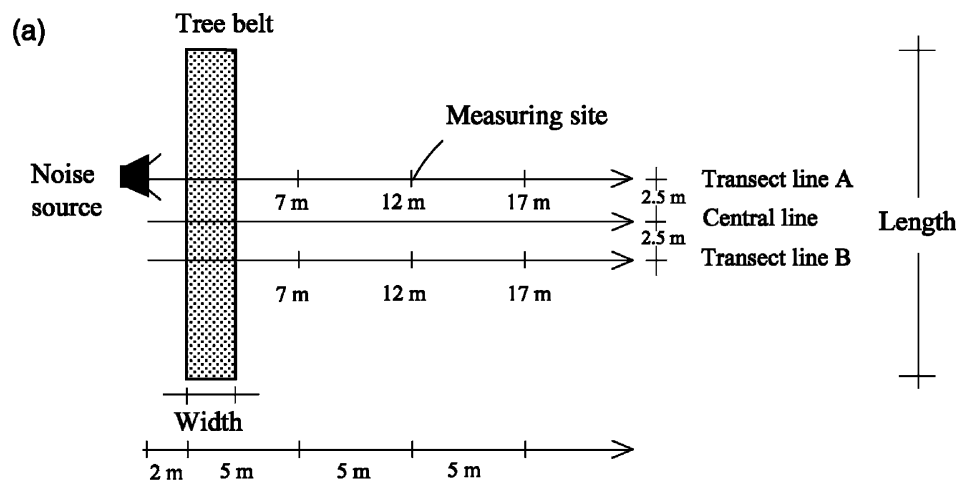

Tree belt

(b)

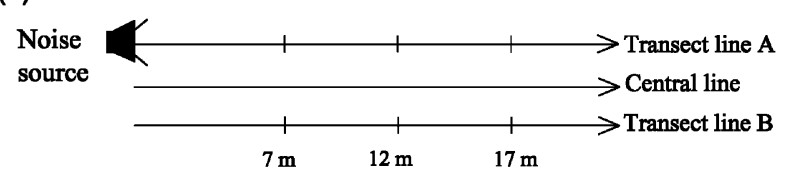

Open ground

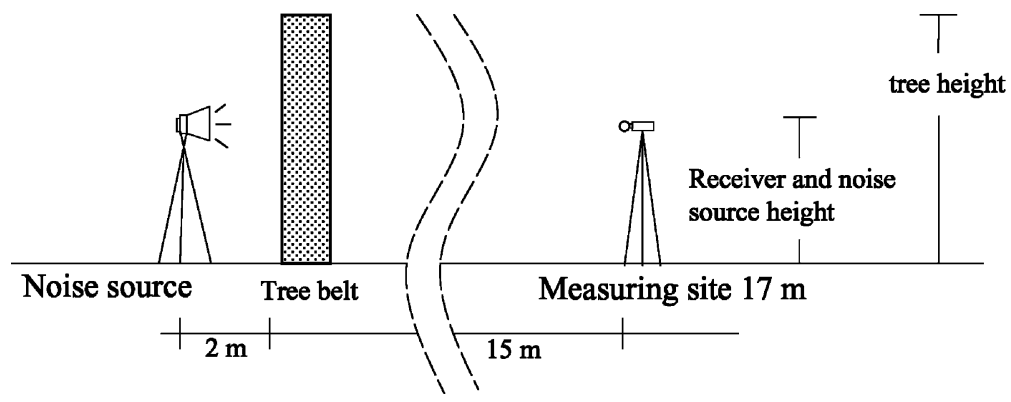

Fig. 1. Diagram of experiment design: (a) the plan of experimental design; (b) the profile of experimental design. 
behind the tree belt and that on the open ground at each corresponding measuring site represents the net noise reduction, or relative attenuation, due to the tree belt. The noise source, method of noise measurement, and the weather conditions used in this study were the same as previously reported by Fang and Ling (2003).

\subsection{Visibility measurement}

The visibility through the tree belt, i.e., the distance that an object is obscured by the plants, was measured to indicate the density of tree leaves and branches of the belt as suggested by Eyring (1946), Embleton (1963), and Fang and Ling (2003). Researcher A stood at one side of the tree belt to be measured while researcher B wearing a white glove stretched his hand into the tree belts on $10 \mathrm{~cm}$ increment until researcher A was unable to see the white glove. The distance between researcher A and B (white glove) at that point was defined as visibility of the tree belt. Two measurements in meters (m) for each belt were averaged.

\subsection{Study procedure}

First, the relative attenuation at each measuring point behind each tree belt was displayed on a map. Next, a multiple regression model based on the data was established to show the relative importance of various factors of the tree belt in noise reduction. In this model, the dependent factor was relative attenuation and independent factors were visibility, tree height, belt width, receiver and noise source height, and distance. Subsequently, the five parameters (independent factors) in the regression model were incorporated, so that the unit of the incorporated parameters was nullified. Three-dimensionless parameters were therefore obtained. They are $h^{\prime}$ (receiver and noise source height/tree height), $d^{\prime}$ (distance/tree height) and $m^{\prime}$ (belt width/visibility). The relationship between relative attenuation and $d^{\prime}$ at various $h^{\prime}(0.15,0.3,0.6)$ were analyzed. Finally, a three-dimensionless map using coordinate axis $X$, $Y$ and $Z$ to represent $m^{\prime}, h^{\prime}$ and $d^{\prime}$ was constructed. The relative attenuation at each measuring site was plotted on the coordinate axis and a noise reduction map of tree belts was finalized based on the curve fitting.

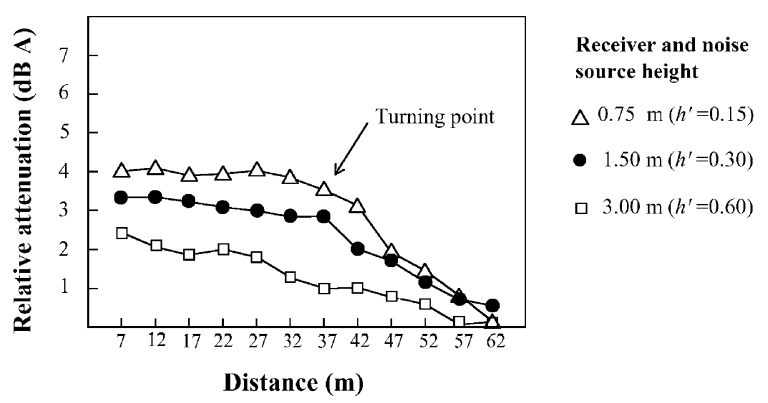

Fig. 2. The noise reduction effect of Casuarina equisetifolia tree belt.

\section{Results}

\subsection{Typical distribution of relative attenuation}

The relative attenuation at various measuring sites of the six tree belts had a similar distribution pattern. Choosing a tree belt of Casuarina equisetifolia as an example, the lower the receiver and noise source height, the greater the noise attenuation (Fig. 2). A turning point existed at a distance approximately $40 \mathrm{~m}$. The relative attenuation declined slowly with increasing distance up to the turning point, but declined rapidly beyond the turning point.

\subsection{Multiple regressive model}

The standardized coefficient (Beta) in the multiple regressive model (Table 2) indicated that the order of relative importance of studied factors was: visibility, belt width, tree height, receiver and noise source

Table 2

Multiple regression model of tree belts and their noise reduction effects

\begin{tabular}{lclr}
\hline Variable & $\begin{array}{l}\text { Unstandardized } \\
\text { coefficients }(B)\end{array}$ & $\begin{array}{l}\text { Standardized } \\
\text { coefficients } \\
\text { (Beta) }\end{array}$ & $t$-value \\
\hline Visibility & -9.28 & -2.68 & $-3.33^{* * *}$ \\
Belt width & 3.75 & 1.25 & $3.88^{* * *}$ \\
Tree height & 2.22 & 0.72 & $3.08^{* * *}$ \\
Receiver and noise & -1.35 & -0.61 & $-10.39^{* * *}$ \\
$\quad$ source height & & & $-7.83^{* * *}$ \\
Distance & -0.06 & -0.52 & 1.79 \\
Constant & 1.83 & & \\
& $R^{2}=0.73$ & $F=54.55$ & \\
& & &
\end{tabular}

*** $P \leq 0.001$. 
height, and distance. The visibility, receiver and noise source height, and distance were negatively correlated, while tree height and belt width were positively correlated with relative attenuation.

\subsection{Relationships between $h^{\prime}, d^{\prime}, m^{\prime}$ and relative attenuation}

Both $d^{\prime}$ and $h^{\prime}$ affect the relative attenuation (Fig. 3). At similar $d^{\prime}$, the smaller the $h^{\prime}$, the greater the relative attenuation. Relative attenuation decreased as $d^{\prime}$ increased. A turning point existed approximately at

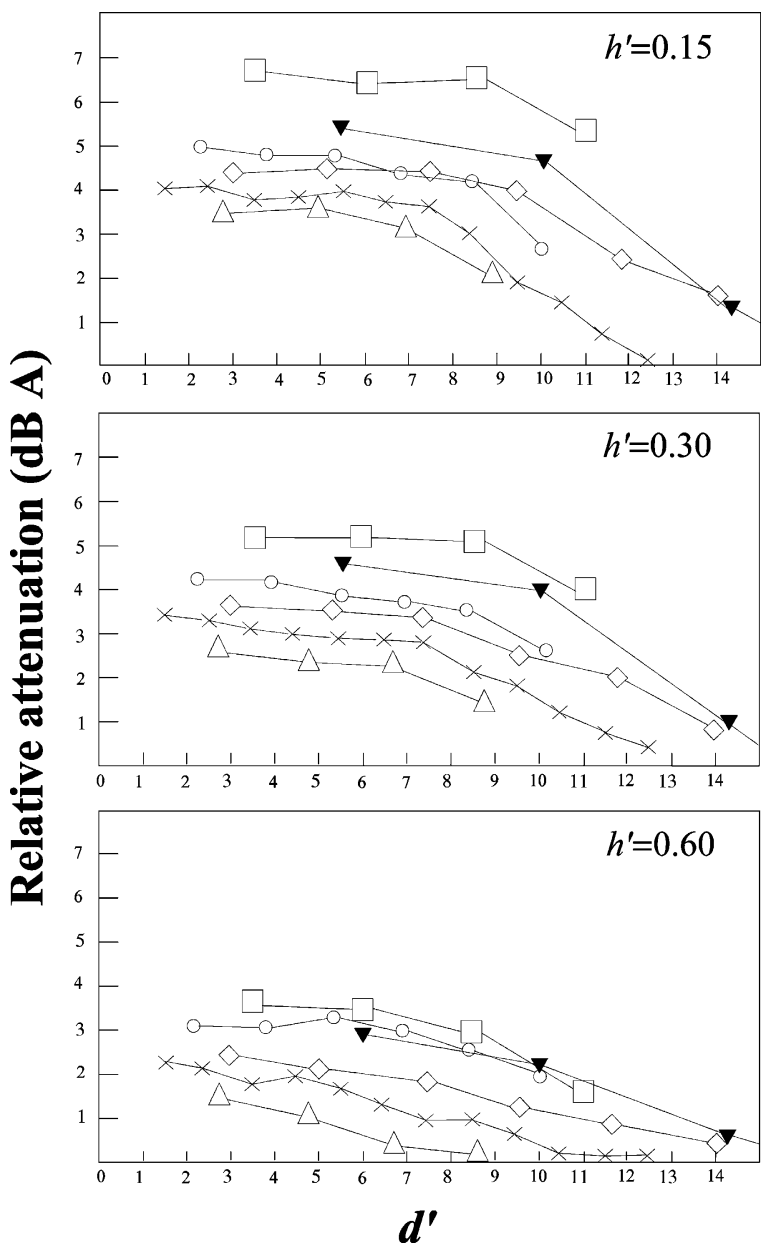

Fig. 3. The noise reduction effect of tree belts with various $d^{\prime}$ and $h^{\prime}$ : $\square$ : Casuarina nana $\left(m^{\prime}=2.5\right)$; ४: Murraya paniculata $\left(m^{\prime}=2.1\right) ; \bigcirc:$ Ficus microcarpa $\left(m^{\prime}=2.0\right) ; \diamond:$ Hibiscus rosa-sinensis $\left(m^{\prime}=1.8\right) ; \times$ : Casuarina equisetiflisa $\left(m^{\prime}=1.6\right)$; $\triangle$ : Duranta repens $\left(m^{\prime}=1.5\right)$. $d^{\prime}=8$ when $h^{\prime}$ was 0.15 or 0.3 . The turning point was less obvious when $h^{\prime}$ was 0.6. Relative attenuation decreased faster beyond the turning point. A map showing the effect of $d^{\prime}, h^{\prime}$ and $m^{\prime}$ on relative attenuation was constructed (Fig. 4). The relative attenuation was lower at the right-top side and higher at the left-bottom side of the map. In other words, the relative attenuation was high when $h^{\prime}$ and $d^{\prime}$ were small and $m^{\prime}$ was large.

\section{Discussion}

When a noise meets a barrier, a noise shadow zone appears behind the barrier. The noise attenuation is high inside the shadow zone, but it is lower outside the shadow zone (Beranek and Vèr, 1992). Therefore, a receiver in the shadow zone can detect a noise reduction effect. The turning point (Fig. 2) found in this study should represent the edge of the noise shadow zone.

Tree height and belt width had positive relationships and visibility had a negative relationships with relative attenuation (Table 2). This result is in agreement with that of Cook and Haverbeke (1974) and Fang and Ling (2003). In addition, a negative relationship exists between the receiver and noise source height and the relative attenuation (Table 2). Since the tree belt as a barrier can cause noise diffraction and therefore lengthen the pathway of the noise, lower receiver and noise height means higher relative tree height, more diffraction effect, longer noise pathway, and greater noise reduction. Negative correlation between distance and the relative attenuation exists because of rapid decline in noise reduction effect beyond the turning point or shadow zone.

Tree belts have good noise reduction effect when $d^{\prime} \leq 8$, and $h^{\prime}=0.15$ or 0.3 (Fig. 3). That is, when the ratio of receiver and noise source height to tree height is 1:6.6 or 1:3.3, an effective noise reduction can be expected within a distance of eight times the tree height. However, the noise reduction effect declines rapidly with $d^{\prime}$ when $h^{\prime}=0.6$, and is significant only within a short distance from the noise source.

The map (Fig. 4) showing the relationships between three-dimensionless parameters and the noise reduction effect indicates that small $h^{\prime}$, large $m^{\prime}$ and $d^{\prime} \leq$ 8 is the effective zone. In other words, a tree belt is 


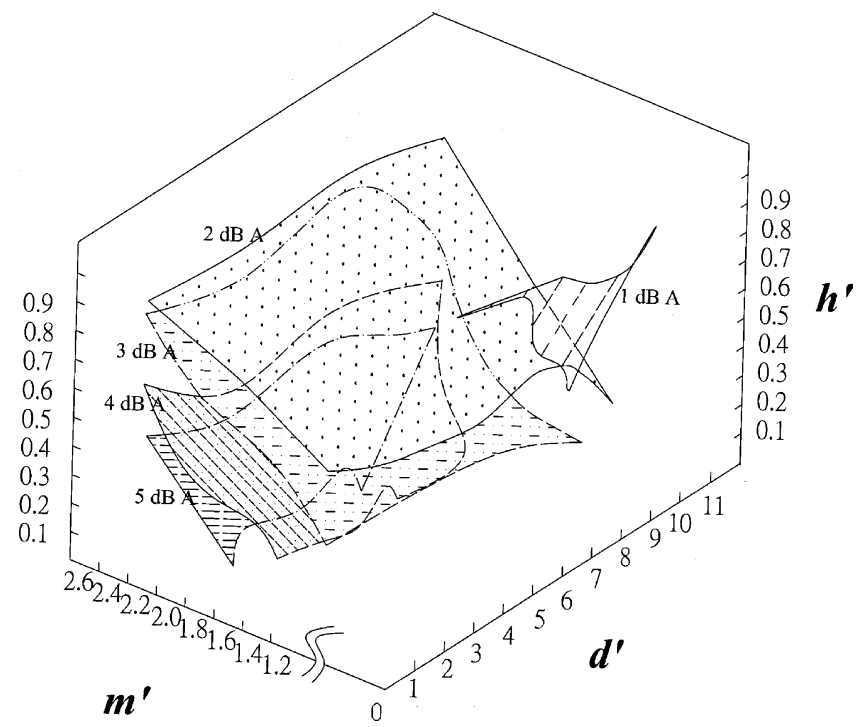

Fig. 4. The relationship between noise reduction and $d^{\prime}, h^{\prime}$ and $m^{\prime}$ dimensionless parameters of tree belts.

effective in noise reduction when both receiver and noise source height and tree belt visibility are low, the tree belt is high and wide, and the distance between the noise source and receiver was less than eight times that of the tree height. Quantitative data in the map may be useful for environmental planning. For example, a noise reduction of $4 \mathrm{~dB} \mathrm{~A}$ is achievable if $m^{\prime}=1.8, d^{\prime}=7$ and $h^{\prime}=0.3$, or $m^{\prime}=1.6, d^{\prime}=$ 4 and $h^{\prime}=0.1$. The former condition is equivalent to a receiver and noise source $1.2 \mathrm{~m}$ high, $28 \mathrm{~m}$ away and a tree belt of $2 \mathrm{~m}$ visibility, $3.6 \mathrm{~m}$ wide and $4 \mathrm{~m}$ high.

Although the noise reduction by a solid wall barrier has been evaluated in terms of Fresnel number (Beranek and Vèr, 1992), this study used a different approach for the tree belts which have many gaps instead of a solid surface. In this work, $h^{\prime}$ was used to evaluate the range of the shadow zone, $d^{\prime}$ to assess the receiver's location in relation to shadow zone, and $m^{\prime}$ to elucidate the porosity of tree belt. By combining the above three-dimensionless parameters in a map (Fig. 4). The noise reduction by a tree belt may be predicted more effectively.

\section{References}

Beranek, L.L., Vèr, I.L., 1992. Noise and Vibration Control Engineering. Wiley/Interscience, New York.

Cook, D.I., Haverbeke, D.F.V., 1974. Trees and shrubs for noise abatement. University of Nebraska College of Agriculture Experiment Station Bulletin, RB246.

Embleton, T.F.W., 1963. Sound propagation in homogeneous deciduous and evergreen woods. J. Acoust. Soc. Am. 35, 11191125.

Eyring, C.F., 1946. Jungle acoustics. J. Acoust. Soc. Am. 18 (2), 257-270.

Fang, C.F., Ling, D.L., 2003. Investigation of the noise reduction provided by tree belts. Landscape Urban Plan. 63 (4), 187-195.

Kragh, J., 1979. Pilot study on railway noise attenuation by belts of trees. J. Sound Vib. 66 (3), 407-415.

Reethof, G., 1973. Effect of plantings on radiation of highway noise. Air Pollut. Control Aso. 23 (3), 185-189. 